\title{
Associations of the neutrophil to lymphocyte ratio with intracranial artery stenosis and ischemic stroke
}

\author{
Liang-Yu Huang ${ }^{1}$, Fu-Rong Sun ${ }^{1}$, Jian-Jun Yin², Ya-Hui Ma ${ }^{1}$, Hong-Qi Li ${ }^{3}$, Xiao-Ling Zhong ${ }^{4}$, Jin-Tai Yu ${ }^{3 *} \mathbb{B}$,
} Jing-Hui Song ${ }^{5^{*}}$ and Lan Tan ${ }^{1 *}$

\begin{abstract}
Background: The neutrophil-to-lymphocyte ratio (NLR) has emerged as an inflammatory marker. However, the associations of NLR with intracranial artery stenosis (ICAS) and ischemic stroke remain unclear. This study aimed to examine the associations of NLR with ICAS and ischemic stroke among a large and high-risk population.

Methods: Participants with records of clinical characteristics were prospectively recruited from the Neurology Department and Health \& Physical Examination Center of Qingdao Municipal Hospital. Logistic regression analysis was used to examine the associations of NLR with ICAS and ischemic stroke. Moreover, we also conducted parametric mediation analysis to estimate the effect of NLR on the risk of ischemic stroke mediated through ICAS.

Results: A total of 2989 participants were enrolled in this study. After adjusting for covariates, NLR (OR=1.125, $95 \% \mathrm{Cl} 1.070-1.183)$ and ICAS $(\mathrm{OR}=1.638,95 \% \mathrm{Cl} 1.364-1.967)$ were significantly associated with ischemic stroke. Compared with the first quartile NLR, the second, third and fourth quartiles NLR were independent risk predictors for ischemic stroke ( $P$ for trend $<0.001$ ); the third and fourth quartiles were independent predictors for ICAS ( $P$ for trend $<0.001)$. The mediation analysis showed that ICAS partially mediated the association between NLR and ischemic stroke, accounting for $14.4 \%$ of the total effect $(P<0.001)$.

Conclusions: NLR was significantly associated with ICAS and ischemic stroke. Besides, ICAS partially mediated the association between NLR and ischemic stroke.
\end{abstract}

Keywords: Intracranial artery stenosis, Ischemic stroke, Neutrophil to lymphocyte ratio, Mediation analysis

\section{Background}

Inflammation has been found to play an vital role in atherosclerosis [1], with various inflammatory parameters being associated with artery stenosis $[2,3]$ as well as

\footnotetext{
*Correspondence: yu-jintai@163.com; jinghuisong@163.com; dr.tanlan@163.com

${ }^{3}$ Department of Neurology and Institute of Neurology, Huashan Hospital, Shanghai Medical College, Fudan University, 12th Wulumuqi Zhong Road, Shanghai 200040, China

${ }^{5}$ Department of Neurology, The Affiliated Hospital of Qingdao University, Qingdao, China

'Department of Neurology, Qingdao Municipal Hospital, Qingdao University, Qingdao 266071, China

Full list of author information is available at the end of the article
}

ischemic events [4-6]. Neutrophil to lymphocyte ratio (NLR) is an indicator of overall systemic inflammatory status in the Asian population and NLR can be of prognostic value in several disorders [7].

Similar to other inflammatory factors, NLR not only serves as an independent risk factor of atherosclerosis in carotid arteries, coronary arteries, and even peripheral arteries [8-11], but also helps to predict the occurrence and prognosis of stroke [12-15]. On the spectrum of atherosclerosis, intracranial artery stenosis (ICAS) was also associated with the inflammatory process. However, the association of NLR with ICAS remains unclear.

(c) The Author(s). 2021 Open Access This article is licensed under a Creative Commons Attribution 4.0 International License, which permits use, sharing, adaptation, distribution and reproduction in any medium or format, as long as you give appropriate credit to the original author(s) and the source, provide a link to the Creative Commons licence, and indicate if changes were made. The images or other third party material in this article are included in the article's Creative Commons licence, unless indicated otherwise in a credit line to the material. If material is not included in the article's Creative Commons licence and your intended use is not permitted by statutory regulation or exceeds the permitted use, you will need to obtain permission directly from the copyright holder. To view a copy of this licence, visit http://creativecommons.org/licenses/by/4.0/ The Creative Commons Public Domain Dedication waiver (http://creativecommons.org/publicdomain/zero/1.0/) applies to the data made available in this article, unless otherwise stated in a credit line to the data. 
Besides, research focusing on the risk of ischemic stroke with the presence of high NLR and ICAS is limited, while the ICAS is one of the most common causes of ischemic stroke [16, 17]. Moreover, the pathogenesis of cerebral atherosclerosis urgently needs to be well addressed for the high prevalence and pathogenicity of ICAS $[18,19]$. Since the NLR is adjustable by controlling inflammation, determining the impact of NLR on the risks of ICAS and ischemic stroke is desired. Such work may contribute to better understanding on the pathophysiological mechanism of ICAS and ischemic stroke as well as exploring new therapeutic targets. Accordingly, this study aimed to examine the differential associations of NLR with ICAS and ischemic stroke among a large and high-risk population.

\section{Methods}

\section{Study design and participants}

Study subjects were prospectively recruited from the Neurology Department and Health Screening Center of Qingdao Municipal Hospital from January 2014 to June 2018. Patients in the department of neurology were diagnosed as suspected acute ischemic stroke. Ischemic stroke is defined as transient ischemic attack (TIA) or acute ischemic stroke (within 7 days of onset). The nonstroke controls enrolled from health screening center were free from serious health problems as well as TIA and acute ischemic stroke. Exclusion criteria for all participants comprised (1) less than 40 years old; (2) incomplete vascular imaging and laboratory tests; (3) evidences of cardioembolic propensity such as history of atrial fibrillation, valvular heart disease, and underwent replacement; (4) intracranial and external artery dissection, arteritis, moyamoya disease, muscular fiber dysplasia; (5) infection, nausea, tumor, chronic liver disease, and renal insufficiency; (6) intracranial or extracranial cerebral artery stenting or balloon angioplasty; (7) hemorrhagic stroke. Written informed consent form was obtained from all participants or their guardians. This study was conducted in accordance with the Declaration of Helsinki and approved by the Institutional Ethics Committees of Qingdao Municipal Hospital.

Finally, a total of 2989 participants who underwent magnetic resonance angiography (MRA) were enrolled in this study, including 1867 participants with ischemic stroke as well as 1122 participants without stroke.

\section{Laboratory measurements}

Fasting blood samples for biochemical analysis were collected within $24 \mathrm{~h}$ after the hospital admission and were measured at the central laboratory of the Qingdao $\mathrm{Mu}$ nicipal Hospital by using an automated analytical platform (Beckman Coulter AU5800: Beckman Coulter Inc. Brea, CA, USA). Fasting blood-glucose and blood fats (high-density lipoprotein, low-density lipoprotein, total cholesterol and triglyceride) were measured using blood samples drawn at approximately $7 \mathrm{a} . \mathrm{m}$. after an overnight fast. Neutrophil count and lymphocyte count in EDTA-anticoagulated whole-blood samples from venipuncture were determined with automated particle counters within the first $24 \mathrm{~h}$ after admission. NLR was calculated as the ratio of neutrophil count to lymphocyte count (NLR = Neutrophil count/Lymphocyte count).

\section{Imaging assessment}

All the included participants had completed magnetic resonance imaging (MRI) and 3D-time-offlight MRA by 3.0-T magnetic resonance to evaluate intracranial artery status. Besides, ultrasonography examination contrastenhanced MRA, or computed tomography angiography (CTA) were performed for evaluating extracranial carotid arteries. According to Warfarin-Aspirin Symptomatic Intracranial Disease (WASID) trial criteria [20], the presence of ICAS was defined as the presence of 5099\% stenosis or the occlusion of intracranial arteries including intracranial section of internal carotid artery (ICA), M1/M2 segment of middle cerebral artery (MCA), A1/A2 segment of anterior cerebral artery (ACA), P1/P2 segment of posterior cerebral artery (PCA), V5 segment of vertebral artery (VA), and basilar artery (BA). Two trained investigators who were blinded to clinical information independently evaluated the presence of ICAS, and a third neuroradiologist was consulted in discussion when disagreements emerging.

\section{Assessment of clinical risk factors}

The clinical characteristics including age, gender, medical histories of coronary heart disease (CHD), hypertension, diabetes mellitus, stroke and drinking were collected in face-to-face interviews by physicians after referral or hospital admission and cross referenced with primary care records. Before the measurement of blood pressure, subjects were required to rest for at least 5 min, and no less than twice measurements were conducted to obtain stable blood pressures. Hypertension was defined as having an average systolic pressure $\geq 140$ $\mathrm{mmHg}$ or an average diastolic pressure $\geq 90 \mathrm{mmHg}$ on $\geq 3$ occasions or taking antihypertensive drugs. Drinking was considered as previous history of or current moderate to severe alcohol consumption (>168 g/week). Smoking was defined as a patient who had smoked continuously for 6 months $\geq 1$ cigarette a day. Diabetes mellitus was defined as having a fasting serum glucose level $\geq 7 \mathrm{mg} / \mathrm{dL}$, a non-fasting serum glucose level $\geq 11.1$ $\mathrm{mg} / \mathrm{dL}$, or use of hypoglycemic agent. CHD was defined as newly diagnosed or a known history of coronary artery disease. 


\section{Statistical analysis}

The main analyses were conducted in 2 steps. Firstly, multivariable logistic regression was used to estimate the odds ratio (OR) of NLR for ischemic stroke. Unadjusted ORs were calculated from a univariable model (model 1). In model 2, age, gender, systolic blood pressure, coronary heart disease, smoking, drinking, glucose, and total cholesterol-adjusted OR was estimated. In model 3, the presence of ICAS was added to model 2. Secondly, to estimate the mediated proportion of the effect of NLR on ischemic stroke, a parametric mediation analysis was conducted. In this mediation analysis, the effect was defined in terms of the difference in regression coefficient by logistic regression models. The total effect (TE) of NLR on ischemic stroke was estimated and was divided into direct effect and the mediated effect (ME) through ICAS. Additionally, the mediated proportion (ie, ME/ TE) was estimated. In the mediation analysis, age, gender, systolic blood pressure, coronary heart disease, smoking, drinking, glucose and total cholesterol were adjusted in the logistic regression model.

As for characteristics of the study participants, the distributions of continuous variables were tested by Kolmogorov-Smirnov tests. Continuous variables without normal distribution were expressed as median (50th) values and interquartile ranges (25th and 75th), compared by the Mann-Whitney U-test. Categorical variables were presented as frequency and percentage, analyzed by $\mathrm{x}^{2}$ test. For the tabulation and logistic regression analysis, SPSS software version 23.0 for Windows (SPSS Inc., Chicago, IL) was used. Mediation analysis was performed using R 3.62version ("lm" function in the package "mediation"). A 2-tailed $P$ value < 0.05 was considered statistically significant.

\section{Results}

Baseline characteristics of study subjects

A total of 2989 individuals (mean age $68.03 \pm 11.37$ years and $39.00 \%$ female) were included in this analysis,

Table 1 Baseline characteristics and neutrophil-to-lymphocyte ratio according to status of ischemic stroke

\begin{tabular}{|c|c|c|c|c|}
\hline & $\begin{array}{l}\text { Total participants included } \\
(n=2989)\end{array}$ & $\begin{array}{l}\text { All participants with stroke } \\
(n=1867)\end{array}$ & $\begin{array}{l}\text { All participants without stroke } \\
(n=1122)\end{array}$ & $P$ \\
\hline Age, mean $\pm S D$, years & $68.03(11.37)$ & $67.96(11.57)$ & $68.16(11.04)$ & 0.717 \\
\hline Female & 1165 (38.98) & $658(35.26)$ & $507(45.23)$ & $0.000^{*}$ \\
\hline $\mathrm{SBP}$, median [IQR], mmHg & 146 [130-160] & 150 [135-165] & 140 [130-155] & $0.000^{*}$ \\
\hline $\mathrm{DBP}$, median $[\mathrm{IQR}], \mathrm{mmHg}$ & 82 [80-90] & 85 [80-92] & 80 [78-90] & $0.000^{*}$ \\
\hline \multicolumn{5}{|l|}{ Hematological examinations } \\
\hline $\begin{array}{l}\text { Glucose, median (IQR), } \\
\mathrm{mmol} / \mathrm{L}\end{array}$ & $5.32(4.67-6.91)$ & $5.47(4.70-7.43)$ & $5.16(4.62-6.36)$ & $0.000^{*}$ \\
\hline $\mathrm{HDL}$, median (IQR), mmol/L & $1.12(0.95-1.33)$ & $1.12(0.95-1.31)$ & $1.12(0.95-1.35)$ & 0.200 \\
\hline $\mathrm{LDL}$, median (IQR), mmol/L & $2.98(2.40-3.57)$ & $3.04(2.48-3.66)$ & $2.85(2.29-3.43)$ & $0.000^{*}$ \\
\hline $\mathrm{TC}$, median (IQR), mmol/L & $4.88(4.10-5.70)$ & $4.95(4.17-5.83)$ & $4.71(3.97-5.33)$ & $0.000^{*}$ \\
\hline $\mathrm{TG}$, median (IQR), mmol/L & $1.29(0.95-1.76)$ & $1.30(0.97-1.78)$ & $1.27(0.91-1.73)$ & $0.035^{\dagger}$ \\
\hline $\begin{array}{l}\text { Neutrophils, median (IQR), } \\
\left(10^{9} / \mathrm{L}\right)\end{array}$ & $3.83(2.99-4.96)$ & $4.05(3.17-5.36)$ & $3.49(2.78-4.37)$ & $0.000^{*}$ \\
\hline $\begin{array}{l}\text { Lymphocytes, median (IQR), } \\
\left(10^{9} / \mathrm{L}\right)\end{array}$ & $1.94(1.52-2.41)$ & $1.94(1.52-2.43)$ & $1.94(1.51-2.40)$ & 0.467 \\
\hline NLR, median (IQR) & $1.92(1.43-2.76)$ & $2.01(1.49-3.00)$ & $1.76(1.33-2.44)$ & $0.000^{*}$ \\
\hline \multicolumn{5}{|l|}{ Medical history } \\
\hline Hypertension, n (\%) & $2370(79.29)$ & $1476(79.06)$ & $894(79.68)$ & 0.685 \\
\hline Diabetes mellitus, n (\%) & $1079(36.10)$ & $694(37.17)$ & $385(34.31)$ & 0.115 \\
\hline Stroke, n (\%) & $711(23.79)$ & $449(24.05)$ & $262(23.35)$ & $0.000^{*}$ \\
\hline CHD, n (\%) & 1141 (38.17) & $628(33.64)$ & $513(45.72)$ & $0.000^{*}$ \\
\hline Smoking, n (\%) & 1015 (33.96) & $690(36.96)$ & $325(28.97)$ & $0.000^{*}$ \\
\hline Drinking, n (\%) & 716 (23.95) & $492(26.35)$ & $224(19.96)$ & $0.000^{*}$ \\
\hline ICAS, n (\%) & $851(28.47)$ & $612(32.78)$ & $239(21.30)$ & $0.000^{*}$ \\
\hline
\end{tabular}

Abbreviations: SBP systolic blood pressure, DBP diastolic blood pressure, HDL high-density lipoprotein, $L D L$ low-density lipoprotein, $T C$ total cholesterol, $T G$ triglyceride, NLR neutrophil to lymphocyte ratio, CHD coronary heart disease, SD standard deviation, IQR interquartile range, $P^{*}$ for comparisons between stroke and non-stroke groups

${ }^{*} P<0.001 ;{ }^{\dagger} P<0.05$ 
among whom 1867 patients with acute ischemic stroke (612 with ICAS and 1255 without ICAS) and 1122 nonstroke controls (239 with ICAS and 883 without ICAS). Clinical characteristics are presented in Table 1. The median NLR level of all participants was 1.92 (interquartile range 1.43-2.76). NLR levels (median 2.01, interquartile range 1.49-3.00) were higher in patients with stroke than those (median 1.76, interquartile range 1.33-2.44, $p<0.001$ ) in controls without stroke. Furthermore, Levels of systolic blood pressure (SBP), diastolic blood pressure (DBP), glucose, low-density lipoprotein (LDL), levels of total cholesterol (TC), and triglyceride (TG); the prevalence of coronary heart disease (CHD) and ICAS; and drinking and smoking frequency were higher in the stroke group than in the non-stroke group.

\section{Associations of NLR with ICAS and ischemic stroke}

The results of the relationship between NLR and Ischemic stroke by logistic regression analysis are shown in Table 2. The univariate OR was 1.163 (95\%CI 1.1071.233) in model 1 . After adjustment for age, gender, systolic blood pressure (SBP), coronary heart disease (CHD), smoking, drinking, glucose, total cholesterol (TC), the ischemic stroke OR with higher NLR was 1.144 (95\%CI 1.088-1.203). In model 3, including all covariates (adjusted in model 2) and ICAS (ie, a mediator), NLR $(\mathrm{OR}=1.125,95 \% \mathrm{CI} 1.070-1.183)$ and ICAS $(\mathrm{OR}=$ $1.638,95 \%$ CI $1.364-1.967)$ were significantly associated with ischemic stroke. Despite the adjustment for ICAS, NLR remained independently associated with ischemic stroke. As shown in Table 3, NLR was also an independent risk factor for ICAS after adjusting age; gender; SBP; history of hypertension, diabetes mellitus, CHD, smoking and drinking; glucose; and high-density lipoprotein. The covariates and ICAS-adjusted results for ICAS and ischemic stroke according to NLR quartiles are shown in Fig. 1. Compared with the first quartile, the second $(\mathrm{OR}=1.276,95 \% \mathrm{CI} 1.030-1.580)$, third $(\mathrm{OR}=1.528$, 95\%CI $1.228-1.903)$ and fourth $(\mathrm{OR}=1.870,95 \% \mathrm{CI}$ $1.487-2.353)$ quartiles were independent risk predictors for ischemic stroke ( $P$ for trend $<0.001)$; the third $(\mathrm{OR}=$ $1.394,95 \% \mathrm{CI} 1.092-1.779)$ and forth $(\mathrm{OR}=2.196,95 \% \mathrm{CI}$ 1.729-2.790) quartiles were independent predictors for ICAS ( $P$ for trend $<0.001)$.

\section{Mediation analysis}

The results of the mediation analysis on the risk of ischemic stroke are depicted in Fig. 2. As TE, NLR significantly associated with ischemic stroke $(\mathrm{TE}=0.016,95 \%$ CI 0.010-0.020); within TE, 0.002 (95\% CI, 0.001-0.003) was estimated to be an ME; and 0.014 (95\% CI, 0.007$0.020)$ was attributed to the direct effect. From these estimates, the proportion of ME in TE was estimated to be $14.4 \%(95 \% \mathrm{CI}, 8.0-26.0 \%)$ : the $14.4 \%$ risk of ischemic stroke associated with NLR was mediated by ICAS.

Table 2 Logistic regression estimation of the effect on ischemic stroke with neutrophil to lymphocyte ratio at baseline

\begin{tabular}{|c|c|c|c|c|c|c|}
\hline & $\begin{array}{l}\text { Model } 1 \\
\text { OR }(95 \% \mathrm{Cl})\end{array}$ & $P$ & $\begin{array}{l}\text { Model } 2 \\
\text { OR }(95 \% \mathrm{Cl})\end{array}$ & $P$ & $\begin{array}{l}\text { Model } 3 \\
\text { OR }(95 \% \mathrm{Cl})\end{array}$ & $P$ \\
\hline Age & $0.999(0.992-1.005)$ & 0.640 & $1.005(0.998-1.013)$ & 0.145 & $1.004(0.996-1.011)$ & 0.304 \\
\hline Gender & $0.660(0.568-0.768)$ & $0.000^{*}$ & $0.723(0.595-0.878)$ & $0.001^{\dagger}$ & $0.706(0.580-0.858)$ & $0.000^{*}$ \\
\hline Systolic blood pressure & $1.018(1.014-1.021)$ & $0.000^{*}$ & $1.016(1.013-1.020)$ & $0.000^{*}$ & $1.016(1.012-1.020)$ & $0.000^{*}$ \\
\hline Hypertension & $0.963(0.802-1.156)$ & 0.685 & & & & \\
\hline Diabetes mellitus & $1.133(0.970-1.322)$ & 0.115 & & & & \\
\hline Stroke history & $1.039(0.873-1.237)$ & 0.664 & & & & \\
\hline Coronary heart disease & $0.602(0.517-0.700)$ & $0.000^{*}$ & $0.578(0.490-0.681)$ & $0.000^{*}$ & $0.575(0.488-0.679)$ & $0.000^{*}$ \\
\hline Smoking & $1.438(1.226-1.686)$ & $0.000^{*}$ & $1.216(0.975-1.517)$ & 0.083 & $1.226(0.982-1.530)$ & 0.072 \\
\hline Drinking & 1.434 (1.199-1.716) & $0.000^{*}$ & $1.055(0.838-1.327)$ & 0.649 & $1.028(0.816-1.295)$ & 0.814 \\
\hline Glucose & $1.090(1.057-1.124)$ & $0.000^{*}$ & $1.081(1.047-1.116)$ & $0.000^{*}$ & $1.072(1.038-1.107)$ & $0.000^{*}$ \\
\hline High-density lipoprotein & $0.938(0.780-1.127)$ & 0.494 & & & & \\
\hline Low-density lipoprotein & $1.001(0.981-1.021)$ & 0.922 & & & & \\
\hline Triglyceride & $1.056(0.984-1.134)$ & 0.132 & & & & \\
\hline Total cholesterol & $1.173(1.104-1.245)$ & $0.000^{*}$ & $1.161(1.088-1.240)$ & $0.000^{*}$ & $1.170(1.095-1.250)$ & $0.000^{*}$ \\
\hline Neutrophil to lymphocyte ratio & $1.163(1.107-1.233)$ & $0.000^{*}$ & $1.144(1.088-1.203)$ & $0.000^{*}$ & $1.125(1.070-1.183)$ & $0.000^{*}$ \\
\hline Intracranial artery stenosis & & & & & $1.638(1.364-1.967)$ & $0.000^{*}$ \\
\hline
\end{tabular}

Model 1: crude; Model 2: adjusted for age, gender, systolic blood pressure, coronary heart disease, smoking, drinking, glucose, total cholesterol

Model 3: model $2+$ adjusted for intracranial artery stenosis

" $P<.001$

${ }^{+} P<.05$ 
Table 3 Logistic regression estimation of the effect on intracranial artery stenosis with neutrophil to lymphocyte ratio at baseline

\begin{tabular}{|c|c|c|c|c|}
\hline & $\begin{array}{l}\text { Model } 1 \\
\text { OR }(95 \% \mathrm{Cl}) \\
\end{array}$ & $P$ & $\begin{array}{l}\text { Model } 2 \\
\text { OR }(95 \% \mathrm{Cl})\end{array}$ & $P$ \\
\hline$\overline{\text { Age }}$ & $1.022(1.015-1.029)$ & $0.000^{*}$ & $1.020(1.012-1.028)$ & $0.000^{*}$ \\
\hline Female & $1.190(1.012-1.398)$ & $0.036^{\dagger}$ & $1.290(1.050-1.585)$ & $0.015^{\dagger}$ \\
\hline Systolic blood pressure & $1.008(1.005-1.012)$ & $0.000^{*}$ & $1.005(1.002-1.009)$ & $0.005^{\dagger}$ \\
\hline Hypertension & $1.387(1.129-1.704)$ & $0.002^{\dagger}$ & $1.192(0.952-1.493)$ & 0.125 \\
\hline Diabetes mellitus & $1.605(1.364-1.888)$ & $0.000^{*}$ & $1.292(1.052-1.587)$ & $0.015^{\dagger}$ \\
\hline Coronary heart disease & $1.190(1.011-1.399)$ & $0.036^{+}$ & $0.943(0.790-1.126)$ & 0.516 \\
\hline Smoking & $0.837(0.706-0.992)$ & $0.040^{\dagger}$ & $0.920(0.728-1.163)$ & 0.487 \\
\hline Drinking & $1.001(0.831-1.206)$ & 0.989 & $1.354(1.063-1.723)$ & $0.014^{\dagger}$ \\
\hline Glucose & $1.086(1.056-1.117)$ & $0.000^{*}$ & $1.053(1.017-1.091)$ & $0.003^{\dagger}$ \\
\hline High-density lipoprotein & $0.689(0.539-0.880)$ & $0.003^{\dagger}$ & $0.646(0.495-0.841)$ & $0.001^{\dagger}$ \\
\hline Low-density lipoprotein & $0.984(0.927-1.044)$ & 0.584 & - & - \\
\hline Triglyceride & $0.953(0.882-1.029)$ & & & \\
\hline Total cholesterol & $0.969(0.910-1.031)$ & 0.319 & - & - \\
\hline Neutrophil to lymphocyte ratio & $1.183(1.133-1.234)$ & $0.000^{*}$ & $1.158(1.108-1.210)$ & $0.000^{*}$ \\
\hline
\end{tabular}

Model 1: Crude; Model 2: Adjusted for age, gender, systolic blood pressure, hypertension, diabetes mellitus, coronary heart disease, smoking, drinking, glucose, high-density lipoprotein

${ }^{*} P<.001$

${ }^{\dagger} P<.05$

\section{Discussion}

The present study showed that NLR was independently associated with ICAS as well as ischemic stroke in a dose-response pattern. Moreover, we found ICAS significantly and partially mediate the association between NLR and ischemic stroke.

Our results are consistent with recent findings from a cohort study based on a healthy population reporting the independent association of NLR with ICAS [21]. Moreover, several studies reported that high NLR had a strong correlation and precise predictability for restenosis after angioplasty and stenting for asymptomatic carotid stenosis [22]. The mechanisms underlying these observations are not well established, but they seem to be related to the different roles of neutrophils and lymphocytes in the pathophysiologic development of atherosclerosis [23]. As an indicator of acute and chronic inflammation, neutrophil plays a positive role in atherosclerosis [24]. Elevated neutrophil count was reported as a predictor of artery stenosis $[25,26]$. A certain number of neutrophils accumulating on the vascular wall can trigger inflammatory reactions through releasing active molecules, such as proinflammatory cytokines and oxyradical, and may lead to endothelial dysfunction and atherogenesis by reducing the utilization of nitrogen oxide [12, 27]. Contrary to neutrophils, lymphocytes
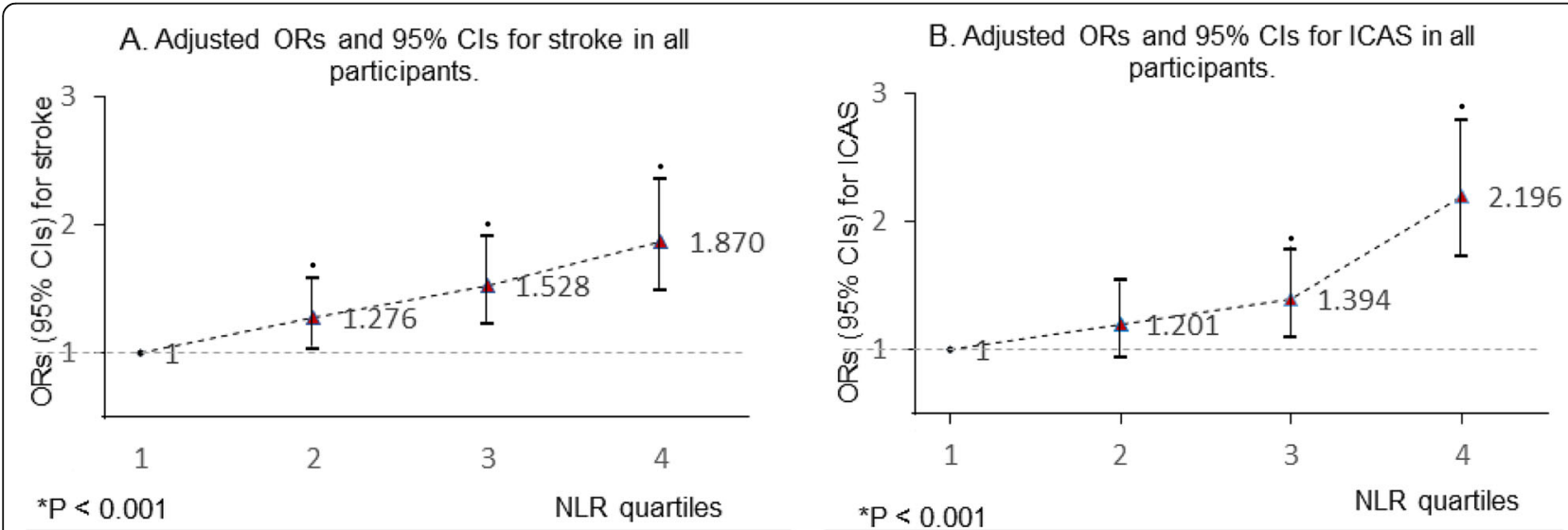

Fig. 1 Multinomial-adjusted ORs and 95\% Cls for ICAS and ischemic stroke according to NLR quartiles. NLR was significantly associated with ischemic stroke in the second, third and fourth quartiles. NLR was significantly associated with ICAS in the third and fourth quartiles in all participants. (the first NLR quartile as reference). $p<<0.05$; ${ }^{*}$ : $p$ value for trend 


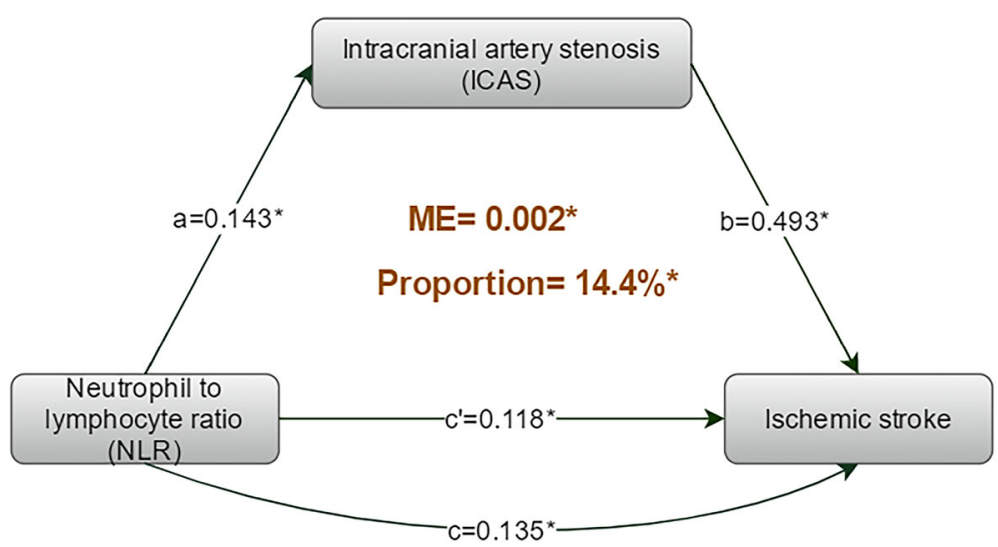

Fig. 2 The results of mediation analysis on the risk of ischemic stroke. The mediation analysis showed that ICAS significantly and partially mediate the association between NLR and ischemic stroke, accounting for $14.4 \%$ of the total effect $(P<0.001)$. ME: mediated effect; a: the adjusted regression coefficient between NLR and ICAS; b: the adjusted regression coefficient between ICAS and ischemic stroke; c: the adjusted (including ICAS) regression coefficient between NLR and ischemic stroke; $c^{\prime}$ : the adjusted (barring ICAS) regression coefficient between NLR and ischemic stroke. ${ }^{*} p<0.001$

have a negative regulatory effect on atherosclerosis. One study indicated that B lymphocytes had protective effects on atherosclerosis caused by hypercholesterolemia [28]. Additionally, lymphocytes are regarded as healing promoters for they secreting anti-inflammatory cytokines interleukin-10 and interleukin-4 [29]. Given their potential roles in plaque formation, it is not surprising that high NLR is significantly associated with ICAS. Besides, both atherosclerosis and ischemic stroke are results of a combination of a variety of risk factors including smoking, alcohol abuse, dyslipidemia, diabetes, and hypertension [30, 31], and several of these risk factors are independently associated with NLR [32-34]. Therefore, NLR may associated with ICAS and ischemic stroke through larger burdens of various vascular risk factors.

Nasr et al' study has reported significant association of neutrophil count with microembolization in patients with symptomatic carotid artery stenosis [35]. In addition, existing studies points that NLR is significantly correlated with non-calcified plaques [36, 37], which are less stable and more rupture-prone than calcified plaques. Moreover, evidence from human atherosclerosis specimens and murine models of atherosclerosis suggests the presence of neutrophils and neutrophil-derived mediators in atherosclerotic lesions [38, 39]. All these evidences indicate that NLR may participant in plaque rupture, which can well explain the results of mediation analysis in the present study. For one thing, in addition to the mechanisms mediated by active molecules released from neutrophils, novel aspects of neutrophil biology may also contribute to ischemic brain injury. Activated neutrophils have been recently described as components of neutrophil extracellular traps (NETs), which are web-like extracellular scaffolds consisting of DNA, histones, and specific granule proteins, such as neutrophil elastase and myeloperoxidase, in response to various stimuli [40]. Recent evidence indicates that NETs may serve harmful contributors during myocardial and liver ischemia/ reperfusion (I/R) injury and the absence of NETs offers significant cardioprotective, hepatoprotective, and anti-inflammatory effects [41]. These results suggest that NETs may play a role tissue damage. For another, lymphopenia (decreased lymphocyte counts in circulation), resulting from elevated corticosteroids under stress conditions in atherosclerosis patients [42], may cause a weakened healing effects on atherosclerosis.

The NLR reflects the balance between neutrophil and lymphocyte levels, which may be comprehensively represent the immunological conditions; using NLR rather than leukocyte count is the specialty of our study. There were still several limitations. First, we cannot rule out the possibility that there were patients with congenital ICAS and arterial dissection in our subjects. At the same time, 3D MRA may not precise enough to evaluate ICAS. Second, the enrolled participants may all have atheromatous intracranial stenosis vs other causes, which is linked to Asian geographical origin of the study population; on this point, we should explain the present results with caution in other population. Third, although we have considered many traditional risk factors, there are still some confounding factors that are not included in this study. Fourth, we could not conclude the causal relationship between NLR and ICAS as well as ischemic stroke, because the level of NLR was not assessed before the onset. So, more conclusive data from well-designed longitudinal studies are needed to understand the mechanism and long-term effect of NLR on the ICAS and ischemic stroke. 


\section{Conclusions}

To summary, the current study demonstrated that NLR was significantly associated with ICAS and ischemic stroke in a dose-response pattern; ICAS partially mediated the association between NLR and ischemic stroke.

\begin{abstract}
Abbreviations
NLR: Neutrophil to lymphocyte ratio; ICAS: Intracranial artery stenosis; MRI: Magnetic resonance imaging; MRA: Magnetic resonance angiography; CHD: Coronary heart disease; OR: Odds ratio; Cl: Confidence interval; TE: Total effect; ME: Mediated effect; SBP: Systolic blood pressure; DBP: Diastolic blood pressure; LDL: Low-density lipoprotein; TC: Levels of total cholesterol; TG: Triglyceride; NETs: Neutrophil extracellular traps
\end{abstract}

\section{Acknowledgements}

We thank all patients and controls for their participation in this study.

\section{Authors' contributions}

JTY and LT designed the study and wrote the manuscript. LYH and YHM performed the analysis and interpretation of data as well as manuscript writing. FRS, JJY, HQL, XLZ, and JHS were responsible for the acquisition and interpretation of data and the manuscript revision. The author(s) read and approved the final manuscript

\section{Funding}

This study was supported by grants from the Taishan Scholars Program of Shandong Province (ts201511109 and tsqn20161079) and Qingdao Key Health Discipline Development Fund.

\section{Availability of data and materials}

The datasets used and analysed during the current study available from the corresponding author on reasonable request.

\section{Ethics approval and consent to participate}

This study was approved by the ethic committee of Qingdao Municipal Hospital. Written informed consent form was obtained from all participants or their guardians. This study was conducted in accordance with the Declaration of Helsinki and approved by the Institutional Ethics Committees of Qingdao Municipal Hospital.

\section{Consent for publication}

Not applicable.

\section{Competing interests}

The authors declare that they have no competing interests.

\section{Author details}

'Department of Neurology, Qingdao Municipal Hospital, Qingdao University, Qingdao 266071, China. 'Department of Neurology, Qingdao Hiser Hospital, Qingdao University, Qingdao, China. ${ }^{3}$ Department of Neurology and Institute of Neurology, Huashan Hospital, Shanghai Medical College, Fudan University, 12th Wulumuqi Zhong Road, Shanghai 200040, China. ${ }^{4}$ Department of Neurology, Qingdao Central Hospital, Qingdao University, Qingdao, China. ${ }^{5}$ Department of Neurology, The Affiliated Hospital of Qingdao University, Qingdao, China.

Received: 6 October 2020 Accepted: 24 January 2021

Published online: 05 February 2021

\section{References}

1. Fava C, Montagnana M. Atherosclerosis Is an Inflammatory Disease which Lacks a Common Anti-inflammatory Therapy: How Human Genetics Can Help to This Issue. A Narrative Review. Front Pharmacol. 2018:9:55. https:// doi.org/10.3389/fphar.2018.00055

2. Tousoulis D, Oikonomou E, Economou EK, Crea F, Kaski JC. Inflammatory cytokines in atherosclerosis: current therapeutic approaches. Eur Heart J. 2016:37(22):1723-32. https://doi.org/10.1093/eurheartj/ehv759.

3. Geng S, Chen K, Yuan R, Peng L, Maitra U, Diao N, et al. The persistence of lowgrade inflammatory monocytes contributes to aggravated atherosclerosis. Nat Commun. 2016;7:13436. https://doi.org/10.1038/ncomms13436.
4. McColl BW, Allan SM, Rothwell NJ. Systemic infection, inflammation and acute ischemic stroke. Neuroscience. 2009;158(3):1049-61. https://doi.org/10. 1016/j.neuroscience.2008.08.019.

5. Grau A, Boddy AW, Dukovic DA, Buggle F, Lichy C, Brandt T, et al. Leukocyte count as an independent predictor of recurrent ischemic events. Stroke. 2004; 35(5):1147-52. https://doi.org/10.1161/01.STR.0000124122.71702.64.

6. Esenwa CC, Elkind MS. Inflammatory risk factors, biomarkers and associated therapy in ischaemic stroke. Nat Rev Neurol. 2016;12(10):594-604. https:// doi.org/10.1038/nrneurol.2016.125.

7. Pikija S, Sztriha LK, Killer-Oberpfalzer M, Weymayr F, Hecker C, Ramesmayer C, et al. Neutrophil to lymphocyte ratio predicts intracranial hemorrhage after endovascular thrombectomy in acute ischemic stroke. J Neuroinflammation. 2018:15(1):319. https://doi.org/10.1186/s12974-018-1359-2.

8. Mayer FJ, Gruenberger D, Schillinger M, Mannhalter C, Minar E, Koppensteiner $\mathrm{R}$, et al. Prognostic value of neutrophils in patients with asymptomatic carotid artery disease. Atherosclerosis. 2013;231(2):274-80. https://doi.org/10.1016/j.atherosclerosis.2013.10.002.

9. Hyun S, Kwon S, Cho S, Park S, Jung W, Moon S, et al. Can the neutrophilto-lymphocyte ratio appropriately predict carotid artery stenosis in patients with ischemic stroke?-a retrospective study. J Stroke Cerebrovasc Dis. 2015; 24(11):2646-51. https://doi.org/10.1016/j.jstrokecerebrovasdis.2015.07.024.

10. Tamhane UU, Aneja S, Montgomery D, Rogers EK, Eagle KA, Gurm HS. Association between admission neutrophil to lymphocyte ratio and outcomes in patients with acute coronary syndrome. Am J Cardiol. 2008; 102(6):653-7. https://doi.org/10.1016/i.amjcard.2008.05.006.

11. Meng LB, Yu ZM, Guo P, Wang QQ, Qi RM, Shan MJ, et al. Neutrophils and neutrophil-lymphocyte ratio: inflammatory markers associated with intimalmedia thickness of atherosclerosis. Thromb Res. 2018;170:45-52. https://doi. org/10.1016/j.thromres.2018.08.002.

12. Saliba W, Barnett-Griness O, Elias M, Rennert G. Neutrophil to lymphocyte ratio and risk of a first episode of stroke in patients with atrial fibrillation: a cohort study. J Thromb Haemost. 2015;13(11):1971-9. https:/doi.org/10.1111/jth.13006.

13. Farah R, Samra N. Mean platelets volume and neutrophil to lymphocyte ratio as predictors of stroke. J Clin Lab Anal. 2018;32:1. https://doi.org/10.1002/jcla.22189.

14. Zhang WB, Zeng YY, Wang F, Cheng L, Tang WJ, Wang XQ. A high neutrophil-to-lymphocyte ratio predicts hemorrhagic transformation of large atherosclerotic infarction in patients with acute ischemic stroke. Aging. 2020;12(3):2428-39. https://doi.org/10.18632/aging.102752.

15. Nam KW, Kim TJ, Lee JS, Kwon HM, Lee YS, Ko SB, et al. High neutrophil-tolymphocyte ratio predicts stroke-associated pneumonia. Stroke. 2018;49(8): 1886-92. https://doi.org/10.1161/strokeaha.118.021228.

16. Amarenco P, Steering C. Investigators of the ToP. Five-Year Risk of Stroke after TIA or Minor Ischemic Stroke. N Engl J Med. 2018;379(16):1580-1. https://doi.org/10.1056/NEJMc1808913.

17. Holmstedt CA, Turan TN, Chimowitz MI. Atherosclerotic intracranial arterial stenosis: risk factors, diagnosis, and treatment. Lancet Neurol. 2013;12(11): 1106-14. https://doi.org/10.1016/S1474-4422(13)70195-9.

18. Gorelick PB, Wong KS, Bae HJ, Pandey DK. Large artery intracranial occlusive disease: a large worldwide burden but a relatively neglected frontier. Stroke. 2008;39(8):2396-9. https://doi.org/10.1161/STROKEAHA.107.505776.

19. Hurford R, Wolters FJ, Li L L Lau KK, Kuker W, Rothwell PM, et al. Prevalence, predictors, and prognosis of symptomatic intracranial stenosis in patients with transient ischaemic attack or minor stroke: a population-based cohort study. Lancet Neurol. 2020;19(5):413-21. https://doi.org/10.1016/S1474-4422(20)30079-X.

20. Samuels OB, Joseph GJ, Lynn MJ, Smith HA, Chimowitz MI. A standardized method for measuring intracranial arterial stenosis. AJNR Am J Neuroradiol. 2000:21(4):643-6.

21. Nam KW, Kwon HM, Jeong HY, Park JH, Kim SH, Jeong SM. High neutrophil to lymphocyte ratios predict intracranial atherosclerosis in a healthy population. Atherosclerosis. 2018;269:117-21. https://doi.org/10.1016/j. atherosclerosis.2017.12.035.

22. Dai Z, Li R, Zhao N, Han Y, Wang M, Zhang S, et al. Neutrophil to lymphocyte ratio as a predictor of restenosis after angioplasty and stenting for asymptomatic carotid stenosis. Angiology. 2019;70(2):160-5. https://doi. org/10.1177/0003319718784805.

23. Bakogiannis C, Sachse M, Stamatelopoulos K, Stellos K. Platelet-derived chemokines in inflammation and atherosclerosis. Cytokine. 2019;122:154157. https://doi.org/10.1016/j.cyto.2017.09.013.

24. Moschonas IC, Tselepis AD. The pathway of neutrophil extracellular traps towards atherosclerosis and thrombosis. Atherosclerosis. 2019:288.9-16. https://doi.org/10.1016/j.atherosclerosis.2019.06.919. 
25. Guven R, Akyol KC, Bayar N, Gungor F, Akca AH, Celik A. Neutrophil count as a predictor of critical coronary artery stenosis in young patients. Iran J Public Health. 2018;47(5):765-7.

26. Zhu B, Liu H, Pan Y, Jing J, Li H, Zhao X, et al. Elevated neutrophil and presence of intracranial artery stenosis increase the risk of recurrent stroke. Stroke. 2018; 49(10):2294-300. https://doi.org/10.1161/STROKEAHA.118.022126.

27. Qi H, Yang S, Zhang L. Neutrophil extracellular traps and endothelial dysfunction in atherosclerosis and thrombosis. Front Immunol. 2017:8:928. https://doi.org/10.3389/fimmu.2017.00928.

28. Doran AC, Lipinski MJ, Oldham SN, Garmey JC, Campbell KA, Skaflen MD, et al. B-cell aortic homing and atheroprotection depend on Id3. Circ Res. 2012;110(1):e1-12. https://doi.org/10.1161/CIRCRESAHA.111.256438.

29. Vila N, Castillo J, Davalos A, Esteve A, Planas AM, Chamorro A. Levels of antiinflammatory cytokines and neurological worsening in acute ischemic stroke. Stroke. 2003:34(3):671-5. https://doi.org/10.1161/01.STR.0000057976.53301.69.

30. Ma YH, Leng XY, Dong Y, Xu W, Cao XP, Ji X, et al. Risk factors for intracranial atherosclerosis: a systematic review and meta-analysis. Atherosclerosis. 2019; 281:71-7. https://doi.org/10.1016/j.atherosclerosis.2018.12.015.

31. Peters SA, Huxley RR, Woodward M. Diabetes as a risk factor for stroke in women compared with men: a systematic review and meta-analysis of 64 cohorts, including 775,385 individuals and 12,539 strokes. Lancet (London, England). 2014;383(9933): 1973-80. https:/doi.org/10.1016/S0140-6736(14)60040-4.

32. Guo X, Zhang S, Zhang Q, Liu L, Wu H, Du H, et al. Neutrophil:lymphocyte ratio is positively related to type 2 diabetes in a large-scale adult population: a Tianjin chronic low-grade systemic inflammation and health cohort study. Eur J Endocrinol. 2015;173(2):217-25. https://doi.org/10.1530/EJE-15-0176.

33. Jhuang YH, Kao TW, Peng TC, Chen WL, Li YW, Chang PK, et al. Neutrophil to lymphocyte ratio as predictor for incident hypertension: a 9-year cohort study in Taiwan. Hypertens Res. 2019;42(8):1209-14. https://doi.org/10.1038/ s41440-019-0245-3.

34. Liu CC, Ko HJ, Liu WS, Hung CL, Hu KC, Yu LY, et al. Neutrophil-tolymphocyte ratio as a predictive marker of metabolic syndrome. Medicine. 2019;98(43):e17537. https://doi.org/10.1097/MD.0000000000017537.

35. Nasr N, Ruidavets JB, Arnal JF, Sie P, Larrue V. Association of neutrophil count with microembolization in patients with symptomatic carotid artery stenosis. Atherosclerosis. 2009;207(2):519-23. https://doi.org/10.1016/j. atherosclerosis.2009.05.003.

36. Yuksel IO, Koklu E, Arslan S, Cagirci G, Goksu EO, Koc P, et al. Association of Neutrophil/lymphocyte ratio with plaque morphology in patients with asymptomatic intermediate carotid artery stenosis. Korean Circ J. 2016;46(5): 699-705. https://doi.org/10.4070/kcj.2016.46.5.699.

37. Nilsson L, Wieringa WG, Pundziute G, Gjerde M, Engvall J, Swahn E, et al. Neutrophil/Lymphocyte ratio is associated with non-calcified plaque burden in patients with coronary artery disease. PLoS One. 2014;9(9):e108183. https://doi.org/10.1371/journal.pone.0108183.

38. Yvan-Charvet $L$, Welch C, Pagler TA, Ranalletta M, Lamkanfi M, Han S, et al. Increased inflammatory gene expression in $A B C$ transporter-deficient macrophages: free cholesterol accumulation, increased signaling via toll-like receptors, and neutrophil infiltration of atherosclerotic lesions. Circulation. 2008;118(18):1837-47. https://doi.org/10.1161/CIRCULATIONAHA.108.793869.

39. van Leeuwen M, Gijbels MJ, Duijvestijn A, Smook M, van de Gaar MJ, Heeringa $P$, et al. Accumulation of myeloperoxidase-positive neutrophils in atherosclerotic lesions in LDLR-/- mice. Arterioscler Thromb Vasc Biol. 2008;28(1):84-9. https://doi.org/10.1161/ATVBAHA.107.154807.

40. Brinkmann V, Reichard U, Goosmann C, Fauler B, Uhlemann Y, Weiss DS, et al. Neutrophil extracellular traps kill bacteria. Science (New York, NY). 2004;303(5663):1532-5. https://doi.org/10.1126/science.1092385.

41. Huang H, Tohme S, Al-Khafaji AB, Tai S, Loughran P, Chen L, et al. Damageassociated molecular pattern-activated neutrophil extracellular trap exacerbates sterile inflammatory liver injury. Hepatology. 2015;62(2):600-14. https://doi.org/10.1002/hep.27841.

42. Koklu E, Yuksel IO, Arslan S, Bayar N, Cagirci G, Gencer ES, et al. Is elevated neutrophil-to-lymphocyte ratio a predictor of stroke in patients with intermediate carotid artery stenosis? J Stroke Cerebrovasc Dis. 2016;25(3): 578-84. https://doi.org/10.1016/j.jstrokecerebrovasdis.2015.10.031.

\section{Publisher's Note}

Springer Nature remains neutral with regard to jurisdictional claims in published maps and institutional affiliations.

\section{Ready to submit your research? Choose BMC and benefit from:}

- fast, convenient online submission

- thorough peer review by experienced researchers in your field

- rapid publication on acceptance

- support for research data, including large and complex data types

- gold Open Access which fosters wider collaboration and increased citations

- maximum visibility for your research: over $100 \mathrm{M}$ website views per year

At BMC, research is always in progress.

Learn more biomedcentral.com/submissions 